$\S=-1$

\title{
Conformal Antenna for Aerodynamic Drag Reduction in Airborne System
}

\author{
Namrutha $\mathbf{U}^{1 *}$, Arun Raaza ${ }^{2}$, Ramesh $\mathrm{S}^{3}$ \\ ${ }^{1,2}$ Dept. of ECE, Vels Institute of Science, Technology \& Advanced Studies, Pallavaram, Chennai - 600117, Tamil Nadu, India. \\ ${ }^{3}$ Dept. of ECE, Valliammai Engineering College, Kattankulathur, Chennai - 603 203, Tamil Nadu, India. \\ *Corresponding author E-mail: namruthau@gmail.com
}

\begin{abstract}
The conformal antenna receives more consideration towards the coverage augmentation of contemporary wireless communication systems. The foremost unprejudiced of conformal antenna is to reduce aerodynamic drag in aircraft. Consequently designing frequency reconfigurable conformal antenna has become a key concern in the airborne system. This article reviews the state-of-the-art conformal antenna design by considering the challenges of reducing the aerodynamic drag in the airborne applications. Microstrip patch antennas represent compact antenna that offer a conformal nature and capability of equipped integration with communication system. In this work, microstrip patch antenna is designed for airborne system for drag reduction. The hybrid particle swarm and cuckoo search optimization algorithm is utilized for the length and width. Then the algorithm values are used for the calculation of effective length. The performance of the proposed method is compared with hybrid artificial neural network and firefly, genetic algorithm and analyzed.
\end{abstract}

Keywords: Conformal Antennas, Airborne Systems, Coverage Augmentation, Microstrip Patch Antenna, Particle Swarm Cuckoo Search Optimization.

\section{Introduction}

The antenna can form part of a specific high-performance airborne system with applications in the realization of frequency hopping radar. For large angular coverage in the azimuthal plane, low profile conformal arrays of rectangular antennas are mounted on singly curved cylindrical surface. The singly curved surface forms as an approximation of the shape of an aircraft wing, fuselage or external pods. Such a design will Synopsis-3 facilitate the use of antenna in defense applications in radar and communication systems to avoid detection by enemy. This mainly devoted to design of frequency agile antennas conformable to both planar and cylindrical surfaces of airborne systems and facilitates specific operational requirements [1-3]. The need for conformal antennas is more pronounced for the large-sized apertures that are necessary for functions like military airborne surveillance radars. A conformal microstrip antenna on a cylindrical surface with low profile has distinct advantage for applications related to fighter and spacecraft [4-7].

There are operational specific applications related to fighter aircraft that require an antenna to conform on its surface like structural, aerodynamic, and space limitation compulsions. Other main reasons for antenna design to conform to the aircraft surface are particularly electromagnetic requirement such as antenna beam shape and angular coverage. Microstrip antenna and arrays conformed to curved [8-11]. Microstrip antennas are employed in a wide range of microwave systems, such as radar, navigation, communication, remote sensing and biomedical systems. The radiating elements in these applications are usually incorporated in array environments that are considered to be planar. More recent developments pursue to mold array antennas into curved surfaces, particular examples being radar antennas integrated into the body of an aircraft, millimeter-wave imaging arrays mounted on un- manned airborne vehicles, and antennas for medical imaging applications which may be required to conform to the shape of the human body [12-15].

Several types of conformal antennas are studied. In particular, cylindrical antennas are analyzed in more detail by varying their physical parameters in order to observe the effects on the performance. After that, the different conformal antennas are directly compared with their planar counterparts. The possibility of conforming them in a determined shape makes them attractive for aircraft, automobiles, ships, where aerodynamic improved by adjusting the antennas to the contour of the vehicles [17-20].

This work mainly focuses on design of conformal microstrip patch antenna at above $1 \mathrm{GHz}$ frequency range in order to avoid the drag in airborne system. The designing parameters are obtained by hybrid particle swarm cuckoo search optimization algorithm [2125]. Finally performance of voltage standing wave ratio, directivity, gain, and the return loss are analyzed.

\section{Design}

The microstrip patch antenna consists of radiating patch and ground plane, the patch is placed on one side of the substrate and ground plane is on another side. The design of patch antenna includes frequency of operation, dielectric material of RT Duroid and dielectric constant is 2.45 . The conformal microstrip patch antenna is presented for the airborne application in order to restrict the drag, in which the microstrip can radiate the electromagnetic waves. The conformal microstrip patch antenna is illustrated in figure 1 . The substrate is place above the ground plane with the height as ' $h$ '. The feeding transmission line is connected along with the patch antenna. The relative permittivity is carried out by the substrate of the patch and the thickness of the patch can be represented as $t$. The frequency range of patch antenna design is 
$1 \mathrm{GHz}$. The power radiated and received from the antenna is depends on the radial distance and angular position [26-30].

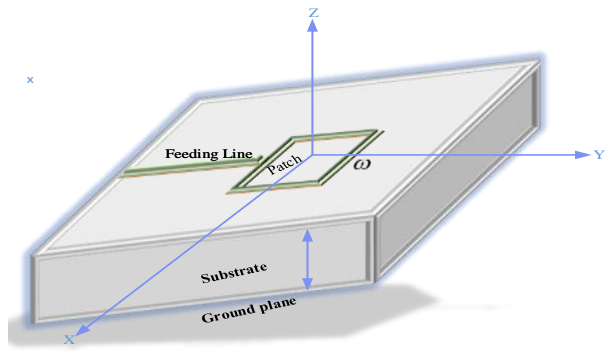

Fig. 1: Conformal Microstrip Patch Antenna

The patch antenna length can be evaluated by [31-33],

$$
\lambda=\frac{C}{2 F r \sqrt{\varepsilon_{\text {reff }}}} \times-2 \Delta \lambda
$$

Where,

$$
\Delta \lambda=0.412 \eta\left(\varepsilon_{\text {reff }}+0.3\right)\left(\frac{\omega}{\eta}+0.264\right) /\left(\varepsilon_{\text {reff }}-0.258\right)\left(\frac{\omega}{\eta}+0.8\right)
$$

The relative permittivity is calculated by,

$$
\varepsilon_{\text {reff }}=\varepsilon_{r}+1 / 2+\varepsilon_{r}-1 / 2 \times 1 / \sqrt{1+12(\eta / \omega)}
$$

The width of the patch antenna can be calculated by,

$$
\omega=C / 2 F r \times \sqrt{\frac{2}{\varepsilon_{r}+1}}
$$

The above equations are used to design the conformal microstrip patch antenna and measure the parameters like radiation pattern, directivity, gain and return loss.

\section{Proposed Algorithm}

The PS-CSO [34] is utilized for optimization of length and width. This algorithm is highly efficient and optimal results are obtained through the algorithm. The steps includes,

Step 1: Initialize the population; it can be represented by,

$$
\alpha=\alpha_{1}, \alpha_{2}, \alpha_{3} \ldots, \alpha_{\eta}
$$

Where the number of particles can be represented as $\alpha_{\eta}$.The population includes upper bound, lower bound, initial velocity and position.

The velocity can be updated by,

$v_{n}(k+1)=\omega v_{n}(k)+\mu_{1} s_{1}\left(p_{n}-\alpha_{n}(k)\right)+\mu_{2} s_{2}\left(p_{g}-\alpha_{n}(k)\right)$

Step 2: The fitness function evaluation is mentioned in equation (1, 2 ). Whereas the fitness value of new and old are compared. The better result is selected for next generation.

Step 3: The population and fitness function can be evaluated through the PSO, in which the global optimal solution can be find out by cuckoo search. In each iteration, the position can be updated by,

$$
\alpha_{n}(k+1)=\alpha_{n}(k)+\lambda \times l(\beta)
$$

Where $\lambda$ denotes the step size parameter, $\alpha_{n}(k)$ is the nest position, $l(\beta)$ random search vector,

Step 4: If the conditions are satisfied then find the optimal solution and corresponding flow chart is shown in figure 2 .

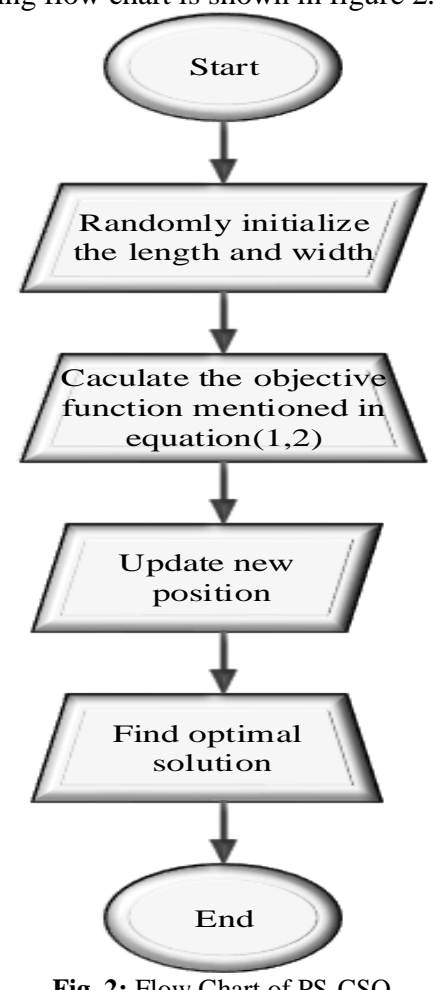

Fig. 2: Flow Chart of PS-CSO

The hybrid algorithm is used to get the optimal length and width to design the microstrip patch antenna. The PSO algorithm is for initial updation, in which the accurate values are updated by the position updation, this can be done through the cuckoo search optimization algorithm. In each iteration, the position values are gets to change.

\section{Results and Discussion}

The below figure 3, shows that the HFSS design of microstrip patch antenna, in which the coordinated like $\mathrm{x}, \mathrm{y}$, and $\mathrm{z}$. The substrate is placed over the ground plane with the particular dimension. The length, width, height and thickness of the dielectric substrate is measured, in which the length and width is measured from the optimization algorithm. The patch length and width is about 25 $\mathrm{mm}$, and $15 \mathrm{~mm}$ respectively.

The return loss of the conformal antenna is shown in figure 4 , in which the loss is reduced at the rate of about $-13.9 \mathrm{~dB}$. The loss is calculated using the equation (3). The difference between upper cut-off frequency and lower cut off frequency is defined in terms of bandwidth. 


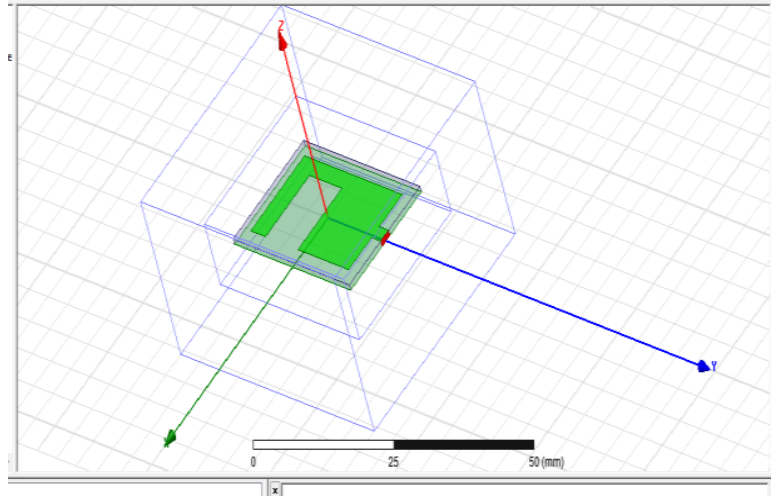

Fig. 3: Design of Conformal Microstrip Patch Antenna

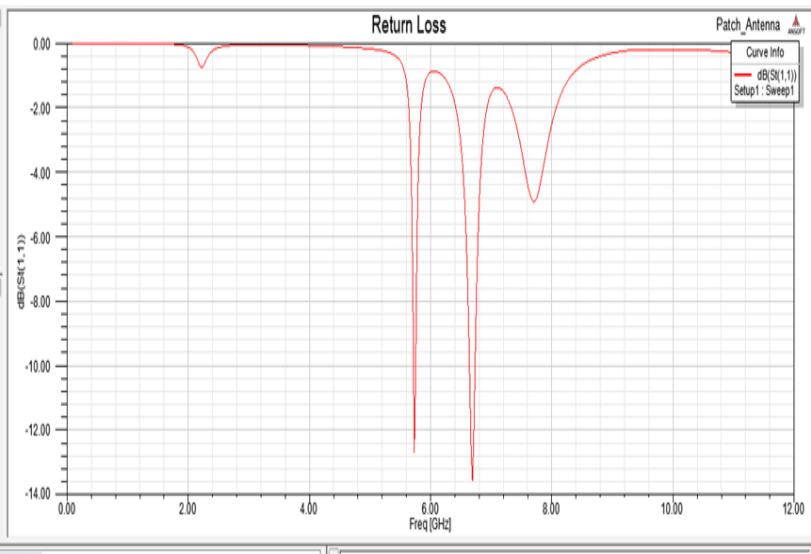

Fig. 4: Return Loss of Conformal Microstrip Patch Antenna

The voltage standing wave ratio(VSWR) is about 1 . The VSWR is always a real and positive number for antennas. The smallest VSWR is, better the antenna is matched to the transmission line and the more power is delivered to the antenna. In this case, no power is reflected from the antenna, which is ideal, which often antennas must satisfy a bandwidth requirement that is given in terms of VSWR and it is shown in figure 5.

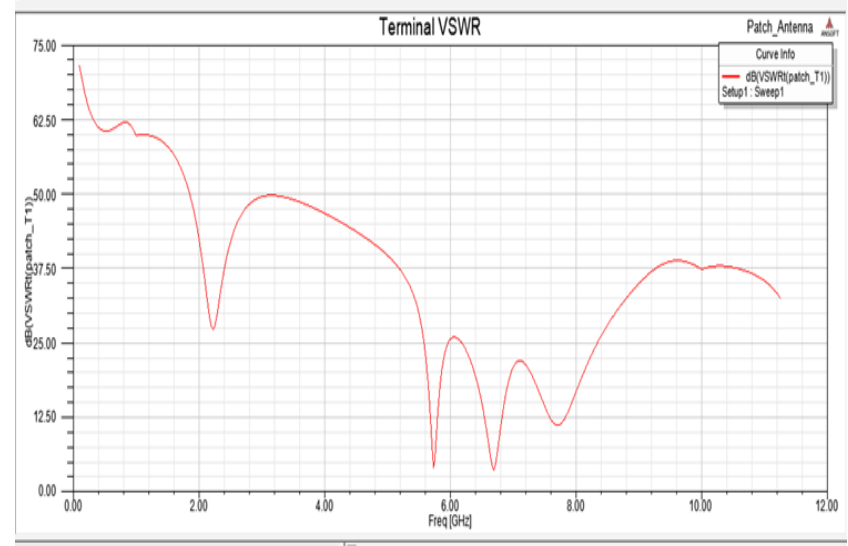

Fig. 5: Voltage Standing Wave Ratio

A transmitting antenna with a gain of $6 \mathrm{~dB}$ resources that the power received far from the antenna will be $6 \mathrm{~dB}$ higher than what would be expected from a lossless isotropic antenna with the same input power. Note that a lossless antenna would be an antenna with an antenna efficiency of $100 \%$. Similarly, a receive antenna with a gain of $6 \mathrm{~dB}$ in a particular direction would receive $6 \mathrm{~dB}$ more power than a lossless isotropic antenna and it is shown in above figure 6 .

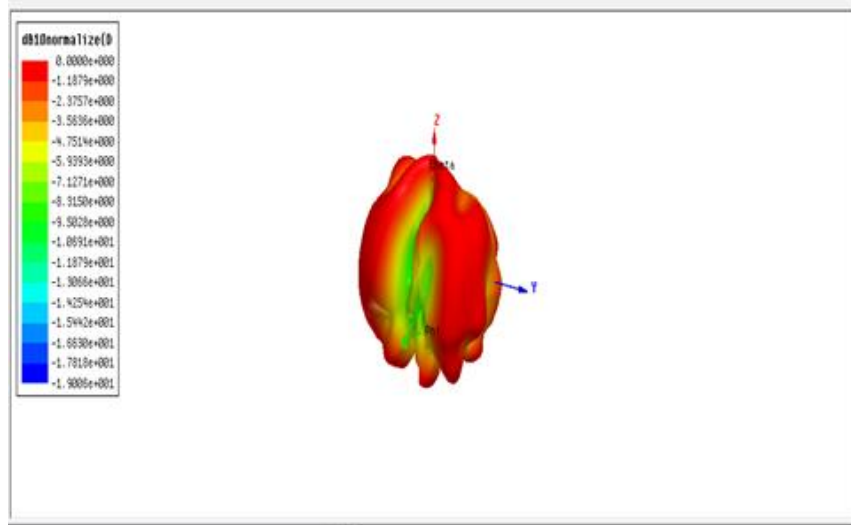

Fig. 6: Directivity of Antenna

The below Table 1 shows that the comparison results of proposed with the existing methods. Thus the comparison results can demonstrate the efficiency of the proposed work and it can have the loss, gain, directivity, and voltage standing wave ratio.

\begin{tabular}{|c|c|c|}
\hline Algorithm & Parameter & Value \\
\hline \multirow{4}{*}{ PSO [35] } & Resonant frequency & $1.95 \mathrm{GHz}$ \\
\hline & Length & $36.43 \mathrm{~mm}$ \\
\hline & Width & $25.79 \mathrm{~mm}$ \\
\hline & Return loss & $-27 \mathrm{~dB}$ \\
\hline \multirow{4}{*}{ GA[36] } & Resonant frequency & $5 \mathrm{GHz}$ \\
\hline & Length & $200 \mathrm{~mm}$ \\
\hline & Width & $100 \mathrm{~mm}$ \\
\hline & Gain & 14.1 \\
\hline \multirow{4}{*}{ AGA [37] } & Resonant frequency & $15 \mathrm{GHz}$ \\
\hline & Length & $16 \mathrm{~mm}$ \\
\hline & Width & $4 \mathrm{~mm}$ \\
\hline & Gain & 15 \\
\hline \multirow[t]{4}{*}{$\mathrm{ABC}[38]$} & Resonant frequency & $1.5 \mathrm{GHz}$ \\
\hline & Length & $6 \mathrm{~cm}$ \\
\hline & Width & $4 \mathrm{~cm}$ \\
\hline & Gain & 16 \\
\hline \multirow[t]{9}{*}{ PSCSO (Proposed) } & Resonant frequency & Above $1 \mathrm{GHz}$ \\
\hline & $\begin{array}{l}\text { Patch Length } \\
\text { Patch Width }\end{array}$ & $\begin{array}{l}15.236 \mathrm{~mm} \\
25.236 \mathrm{~mm}\end{array}$ \\
\hline & $\begin{array}{l}\text { Substrate Length } \\
\text { Substrate Width }\end{array}$ & $\begin{array}{l}12.7 \mathrm{~mm} \\
8.4 \mathrm{~mm}\end{array}$ \\
\hline & $\begin{array}{l}\text { Ground Length } \\
\text { Ground Width }\end{array}$ & $\begin{array}{l}20 \mathrm{~mm} \\
30 \mathrm{~mm}\end{array}$ \\
\hline & $\begin{array}{l}\text { Feed line Length } \\
\text { Feed line Width }\end{array}$ & $\begin{array}{l}20 \mathrm{~mm} \\
30 \mathrm{~mm}\end{array}$ \\
\hline & Return loss & $-13.8 \mathrm{~dB}$ \\
\hline & Gain & $5.4 \mathrm{~dB}$ \\
\hline & Directivity & $7.74 \mathrm{~dB}$ \\
\hline & Voltage standing wave ratio & $9.5 \mathrm{~dB}$ \\
\hline
\end{tabular}

\section{Conclusion}

The conformal patch antenna is successfully designed, simulated and analyzed. The patch antenna with the gain and directivity is highly improved in the proposed system. The radiation pattern of the antenna is designed for the location of airborne system, in order to reduce the drag. The effectiveness of the conformal antenna is checked by the hybrid particle swarm and cuckoo search optimization algorithm. The difference between the upper and lower cut off frequency is the bandwidth and it is about $1.4 \mathrm{GHz}$. The performance of the gain, directivity, voltage standing wave ratio is compared with the existing methods like artificial neural network firefly, genetic algorithm. From the comparison results, we can say the proposed system is better than the existing methods The modern aircraft consists of increased number of antennas which paves the way for drag. Thus the performances of antenna arrays that are used in airborne systems get affected by an aerodynamic drag. This drag has arisen due to the force of an aircraft that 
blocks the aircraft's motion via air. Therefore, conformal antennas are used to minimize the aerodynamic drag in the airborne systems.

\section{References}

[1] Izdebski PM, Rajagopalan H, Rahmat-Samii Y (2009),"Conformal ingestible capsule antenna: A novel chandelier meandered design", IEEE Transactions on Antennas and Propagation, Vol.57, No.4, pp.900-909.

[2] Gomez-Tornero JL (2011),"Analysis and design of conformal tapered leaky-wave antennas', IEEE Antennas and Wireless Propagation Letters, Vol.10, pp.1068-1071.

[3] Sun D, Dou W, You L(2010),"Application of novel cavity-backed proximity-coupled microstrip patch antenna to design broadband conformal phased array", IEEE Antennas and Wireless Propagation Letters, Vol.9, pp.1010-1013.

[4] Lockyer AJ, Alt KH, Coughlin DP, Durham MD, Kudva JN, Goetz AC, Tuss J.,(1999),"Design and development of a conformal loadbearing smart-skin antenna: overview of the AFRL Smart Skin Structures Technology Demonstration (S3TD)", Int. Proc. of SPIE, Vol. 3674, pp. 410-424.

[5] Thors B, Josefsson L(2003)," Radiation and scattering tradeoff design for conformal array", IEEE Transactions on Antennas and Propagation,Vol.5,pp.1069-1076.

[6] Kim Y, Walton EK,(2006)," Automobile conformal antenna design using non-dominated sorting genetic algorithm (NSGA",. IEE Proceedings-Microwaves, Antennas and Propagation, Vol.153, No.6,pp.579-82.

[7] Popa BI, Allen J, Cummer SA.,(2009),"Conformal array design with transformation electromagnetics", Applied Physics Letters, Vol.94, No.24, pp.244-248.

[8] Wincza K, Gruszczynski S, Sachse K.,(2008),'Conformal fourbeam antenna arrays with reduced sidelobes", Electronics Letters, Vol.44, No.3, pp.:174-175

[9] Ouyang J, Yang F, Zhou H, Nie Z, Zhao Z.(2010),"Conformal antenna optimization with space mapping", Journal of Electromagnetic Waves and Applications, Vol.24, No.2, pp.251-260.

[10] Losito O.,(2007),'Design of conformal tapered leaky wave antenna", PIERS online, Vol.3,No.8,pp.:1316-1320

[11] Guo JL, Li JY.,(2009),'Pattern synthesis of conformal array antenna in the presence of platform using differential evolution algorithm", IEEE Transactions on Antennas and Propagation,Vol.57, No.9, pp.2615-2621.

[12] Knott P, Löker C, Algermissen S.,(2011),"Antenna element design for a conformal antenna array demonstrator", IEEE Aerospace Conference, pp.1-5.

[13] Knott P.,(2007),'Design and experimental results of a spherical antenna array for a conformal array demonstrator", IEEE Antennas, INICA'07. 2nd International ITG Conference, pp. 120-123).

[14] Chu LC, Guha D, Antar YM.,(2009),’Conformal strip-fed shaped cylindrical dielectric resonator: Improved design of a wideband wireless antenna", IEEE Antennas and Wireless Propagation Letters, Vol.8,pp.482-485.

[15] Munson R.,(1974),"Conformal microstrip antennas and microstrip phased arrays", IEEE Transactions on Antennas and propagation", Vol.22, No.1, pp.74-78.

[16] Vaskelainen LI, (2007), "Constrained least-squares optimization in conformal array antenna synthesis", IEEE Transactions on Antennas and Propagation, Vol.55, No.3, pp.859-867.

[17] Li WT, Shi XW, Hei YQ, Liu SF, Zhu J., (20100,"A hybrid optimization algorithm and its application for conformal array pattern synthesis", IEEE Transactions on Antennas and Propagation,Vol.58,No.10,pp.3401-3406.

[18] Knott P., (2006),'Design of a triple patch antenna element for double curved conformal antenna arrays", IEEE Antennas and Propagation, EuCAP 2006, pp. 1-4

[19] Yang XS, Qian H, Wang BZ, Xiao S., (2011),'Radiation pattern computation of pyramidal conformal antenna array with activeelement pattern technique", IEEE Antennas and Propagation Magazine,Vol.53, No.1, pp.28-37.

[20] Zhang Z, Gao X, Chen W, Feng Z, Iskander MF.,(2011),"Study of conformal switchable antenna system on cylindrical surface for isotropic coverage", IEEE Transactions on Antennas and Propagation Vol.59, No.3, pp.776-83.

[21] Semkin V, Bisognin A, Kyrö M, Kolmonen VM, Luxey C, Ferrero F, Devillers F, Raisanen AV., (2017),"Conformal antenna array for millimeter-wave communications: performance evaluation", International Journal of Microwave and Wireless Technologies, Vol.9, No.1,pp.241-7.
[22] Emadeddin A, Shad S, Rahimian Z, Hassani HR., (2017),” High mutual coupling reduction between microstrip patch antennas using novel structure", AEU-International Journal of Electronics and Communications, Vol.71,pp.152-156.

[23] S Ramesh, T Rama Rao., (2015)," High gain dielectric loaded exponentially tapered slot antenna array based on substrate integrated waveguide for V-band wireless communications", $A E U$ International Journal of Electronics and Communications, Vol.69, No.1, pp.48-55

[24] De D, Sahu PK., (2017),”A Novel Approach towards the Designing of an Antenna for Aircraft Collision Avoidance System", AEUInternational Journal of Electronics and Communications, Vol.71, No.1, pp.53-71.

[25] Krishna DR, Muthukumar M, Pandharipande VM., (2015),'Design and development of reconfigurable rectangular patch antenna array for tri-band applications", AEU-International Journal of Electronics and Communications, Vol.69, No.1, pp.56-61.

[26] Shim HS, Lee YN, Kim KY,, (2017,"'Optimization of bobsleigh bumper shape to reduce aerodynamic drag", Journal of Wind Engineering and Industrial Aerodynamics, Vol.164,No.1,pp. 108-118.

[27] Eghlima Z, Mansour K,(2017), "Drag reduction for the combination of spike and counter flow jet on blunt body at high Mach number flow", Acta Astronautica, Vol.133, pp.103-110.

[28] McNally J, Fernandez E, Robertson G, Kumar R, Taira K, Alvi F, Yamaguchi Y, Murayama K,(2014), "Drag reduction on a flat-back ground vehicle with active flow control", Journal of Wind Engineering and Industrial Aerodynamics, Vol. 145, No. 1, pp. 292-303.

[29] Liem RP, Martins JR, Kenway GK, (2017) "Expected drag minimization for aerodynamic design optimization based on aircraft operational data", Aerospace Science and Technology, Vol. 63, No.1, pp. 344-362.

[30] Kim T, Shin R, Jung M, Lee J, Park C, Kang S,(2016), “Drag reduction using metallic engineered surfaces with highly ordered hierarchical topographies", Nanostructures on micro-riblets, Applied Surface Science, Vol. 367, No. 1, pp. 147-152.

[31] Singh JM, Mishra M, Sharma P.,(2013),’Design \& Optimization of Microstrip Patch Antenna", International Journal of emerging trends and technology in computer science, Vol.2, No.5, pp.1-5.

[32] Dafalla ZI, Kuan WT, Rahman AA, Shudakar SC.,(2004),'Design of a rectangular microstrip patch antenna at $1 \mathrm{GHz}$ ", IEEE Int. RF and Microwave Conference, RFM 2004, pp. 145-149.

[33] Ramna AS.,(2013),’Design of rectangular microstrip patch antenna using particle swarm optimization", International Journal of Advanced Research in Computer and Communication Engineering Vol.2, No.7, pp.2918-2920.

[34] Singh U, Rattan M.,(2014),’Design of linear and circular antenna arrays using cuckoo optimization algorithm", Progress In Electromagnetics Research C, Vol.46, No.1, pp.1-10.

[35] Sethi KK, Rath S, Tripathy SK, Panigrahi M., (2015),” Application of a Stochastic Approach in the Design of a Rectangular Microstrip Patch Antenna", Procedia Computer Science 2015, Vol. 48, pp.776-780.

[36] Wen YQ, Wang BZ, Ding X., (2016), "A wide-angle scanning and low side lobe level microstrip phased array based on genetic algorithm optimization", IEEE Transactions on Antennas and Propagation, Vol.64, No.2, pp.805-810.

[37] Seong CM, Park DC., (2015),"Study on pattern synthesis of conformal array using enhanced adaptive genetic algorithm", Microwave and Optical Technology Letters, Vol. 57, No.5, pp.1173-1176.

[38] Akdagli A, Bicer MB, Ermis S., (2011),"A novel expression for resonant length obtained by using artificial bee colony algorithm in calculating resonant frequency of C-shaped compact microstrip antennas", Turkish Journal of Electrical Engineering \& Computer Sciences, Vol.19, No.4, pp.597-606.

[39] G. Ramprabu, S. Nagarajan, "Design and Analysis of Novel Modified Cross Layer Controller for WMSN", Indian Journal of Science and Technology, Vol 8(5), March 2015, pp.438-444. 